\title{
A new feather mite of the genus Dolichodectes (Astigmata: Proctophyllodidae) from Hippolais polyglotta (Passeriformes: Acrocephalidae) in Spain
}

\author{
Sergey V. Mironov ${ }^{1}$, Jorge Doña ${ }^{2}$ and Roger Jovani ${ }^{2}$ \\ ${ }^{1}$ Zoological Institute, Russian Academy of Sciences, Saint Petersburg, Russia; \\ ${ }^{2}$ Department of Evolutionary Ecology, Estación Biológica de Doñana (CSIC), Seville, Spain
}

\begin{abstract}
A new feather mite species, Dolichodectes hispanicus sp. n. (Astigmata: Proctophyllodidae), is described from the Melodious Warbler Hippolais polyglotta (Vieillot) (Passeriformes: Acrocephalidae) in Spain. The new species is closest to the type species of the genus, D. edwardsi (Trouessart, 1885) from the Grear Reed-Warbler Acrocephalus arundinaceus (Linnaeus) (Acrocephalidae). Adults of $D$. hispanicus differ from those of $D$. edwardsi by dimensional characteristics, in particular, by having shorter aedeagus that does not extend to the anal suckers in males and shorter hysteronotal shield in females. Tritonymphs of $D$. hispanicus are much more distinctive and differ from those of $D$. edwardsi by having the prodorsal shield covering all the prodorsum, the hysteronotal shield occupying about three quarters of the hysterosoma, and idiosomal setae $h 3$ being filiform. The morphological description of the new species is augmented by sequence data from the mitochondrial cytochrome $c$ oxidase subunit I gene fragment (COI).
\end{abstract}

Keywords: Acari, Pterodectinae, ectoparasites, systematics, passerines, molecular study, COI

The feather mite genus Dolichodectes Park et Atyeo, 1971 (Astigmata: Proctophyllodidae) was established in a generic revision of the subfamily Pterodectinae (Park and Atyeo 1971), and to date it has included eight species (Mironov and Fain 2003, Mironov et al. 2010, 2012). In the subfamily Pterodectinae, this genus and four more genera, Alaudicola Mironov, 1996, Anisodiscus Gaud et Mouchet, 1957, Montesauria Oudemans, 1905 and Pedanodectes Park et Atyeo, 1971, constitute the Montesauria generic complex, which can be considered derived pterodectines of the Old World (Mironov 2009). Within this complex, the genus Dolichodectes is clearly characterised by having a greatly elongated body in both sexes, and strongly elongated opisthosomal lobes, setae ps 3 situated posterior to the anal suckers and bases of setae $g$ and $p s 3$ arranged in a long rectangle in males (Park and Atyeo 1971, Mironov 2009). As for most pterodectine genera, excluding some specialised genera associated with hummingbirds, representatives of this genus inhabit vanes of the primary and secondary feathers of the wings and tail, where they are located in corridors on the ventral surface.

Mites of the genus Dolichodectes have been recorded from representatives of seven passerine families distributed in the Old World: Acrocephalidae, Phylloscopidae, Platysteiridae, Muscicapidae, Turdidae, Ploceidae (Passeroidea) and Monarchidae (Corvoidea). Of eight species previously included in this genus, its type species, Dolichodectes edwardsi (Trouessart, 1885) associated with warblers of the genera Acrocephalus Naumann et Naumann (Acrocephalidae) and Phylloscopus Boie (Phylloscopidae), is widely distributed in the Old World. Dolichodectes bifurcatus Mironov, Literák, Nguen et Čapek, 2012 is known from Copsychus malabaricus (Scopoli) (Muscicapidae) in southeastern Asia, and the six remaining species are recorded only from passerines in Africa (Trouessart 1885, Gaud and Mouchet 1957, Gaud and Till 1961, Mironov 1996, Mironov et al. 2010, 2012). Additionally, Atyeo (1973) reported one undescribed Dolichodectes species from Hippolai calligata (Lichtenstein) (Acrocephalidae) in southeastern Asia. Hernandes and Valim (2006) constructed a key to species of Dolichodectes and described a new species, D. neotropicus Hernandes et Valim, 2006, from a cotinga host (Passeriformes: Cotingidae) in Brazil. Subsequently, these authors (Valim and Hernandes 2009) found out that this species actually belonged to the generic complex of Pterodectes Robin, 1877 and it was removed to a separate genus Berladectes Valim et Hernandes, 2009.

In the present paper, we describe a new Dolichodectes species from the melodious warbler Hippolais polyglotta (Vieillot) (Acrocephalidae) in Spain. The morphological

Address for correspondence: S.V. Mironov, Zoological Institute, Russian Academy of Sciences, Universitetskaya Embankment 1, Saint Petersburg 199034, Russia. Phone: +7 812328 0711; Fax: +7 812328 2941; E-mail: Sergei.Mironov@zin.ru 
description of a new species is complemented by the sequence data on the mitochondrial cytochrome $c$ oxidase subunit I gene fragment (COI) (Doña et al. 2015).

\section{MATERIALS AND METHODS}

Mite specimens used for description were collected from live birds in Spain for our general project 'Quantitative barcoding of birds' feather mites: taxonomy meets ecology' (started in 2012), one of the main goals being to create a barcoding library of feather mites from European passerines (Doña et al. 2015). Mites were manually collected from the feathers using a flattened preparation needle or a cotton swab impregnated with ethanol and preserved at $-20^{\circ} \mathrm{C}$ in tubes with $96 \%$ ethanol. Then mites were mounted on slides for identification in Hoyer's medium according to standard techniques for small mites (Krantz and Walter 2009).

Five mite specimens from different bird individuals were subjected to DNA extraction. After extraction, the exoskeletons were also mounted on slides. DNA extraction, PCR amplification and sequencing were conducted using the protocol described in another paper (Doña et al. 2015). Pairwise genetic distances were calculated in MEGA 6 (Tamura et al. 2013) using the K2P model (Kimura 1980). In addition, we used the Refined Single Linkage (RESL) algorithm to calculate the Barcode Index Number (BIN) (Ratnasingham and Hebert 2013). The mite samples from Hippolais polyglotta were mostly represented by tritonymphs and just a few adults were found; this could be probably explained by the fact that collections from this host were made during migration seasons.

Description of a new species is given according to the modern schemes for pterodectine mites (Hernandes and Valim 2006, Mironov et al. 2008, 2010, 2012, Valim and Hernandes 2010). General morphological terms and leg chaetotaxy follow Gaud and Atyeo (1996); the idiosomal chaetotaxy also follows these authors with corrections to coxal setation added by Norton (1998). All measurements are in micrometres $(\mu \mathrm{m})$. Measuring techniques used for particular structures were recently described in Mironov et al. $(2008,2012)$ and Mironov and González-Acuña (2011). Specimens of Dolichodectes edwardsi, used for comparison in the differential diagnosis, were collected from its type host, the great reed-warbler Acrocephalus arundinaceus (Linnaeus) (Acrocephalidae), in the same locality where the type material of the new species was collected (Doñana National Park, Huelva, Spain).

The taxonomic system and scientific names of birds follows Clements et al. (2014). Specimen deposition is indicated by the following abbreviations: EBD - Estacion Biológica de Doñana (Seville, Spain), ZISP - Zoological Institute of the Russian Academy of Sciences (Saint Petersburg, Russia).

\section{RESULTS}

Family Proctophyllodidae Trouessart et Mégnin, 1884

Subfamily Pterodectinae Park et Atyeo, 1971

Genus Dolichodectes Park et Atyeo, 1971

Dolichodectes hispanicus sp. n.

Figs. 1-3, 4A,B,D
ZooBank number for species:

urn:1sid:zoobank.org:act:CF347684-71FA-430A-9A55-30E1D553CF2B

Male (Figs. 1, 3A-D) (holotype, measurement for 1 paratype in parentheses). Length of idiosoma 515 (520), width 165 (170), length of hysterosoma 355 (360). Prodorsal shield: anterior margin with triangular rostral process, anterolateral extensions connected to bases of epimerites Ia, lateral margins without incisions around scapular setae, posterior margins slightly convex, posterior part with transverse striae near posterior margin, length along midline excluding rostrum 130 (125), width at posterior margin 110 (115) (Fig. 1A). Setae ve represented by alveoli. Bases of scapular setae se separated by 70 (68). Humeral shields absent. Setae $c p$ and $c 2$ situated on soft tegument. Setae $c 3$ lanceolate, $22(21) \times 7$ (8). Hysteronotal shield: greatest length from anterior margin to lobar apices 360 (365), width at anterior margin 135 (140), anterior margin shallowly concave, anterior angles rounded, anterior half of this shield with transverse striae, area from level of trochanters IV to bases of opisthosomal lobes with small longitudinal lacunae. Opisthosomal lobes nearly 3 times longer than wide at base, lateral margins at level of setae $h 2$ noticeably convex, posterior end of each lobe with small acute extension. Terminal cleft a narrow almost parallelsided slit, lateral margins touching, length 78 (84), greatest width in anterior half 5-8. Supranal concavity short, with heavily sclerotised margins. Setae $f 2$ and $p s 2$ situated at same transverse level. Setae $h l$ situated at level of supranal concavity, approximately equidistant from levels of setae $f 2$ and setae $e 2$. Setae $h 3$ lanceolate with acute tips, situated approximately equidistant from lobar apices and bases of setae $h 2$, length 57 (55), greatest width 12 (13); setae ps 260 (65) long, slightly extending beyong to lobar apices; setae ps 1 filiform, minute, about 10 long. Distance between bases of dorsal setae: $c 2: d 2130$ (125), d2:e2 93 (90), e2:h2 73 (66), h2:h3 27 (31),d1:d2 45 (55), e1:e2 22 (24), h1:h2 44 (45),ps1:h3 11 (12), h2:h2 55 (62), h3:h3 27 (25), ps2:ps2 62 (66).

Epimerites I fused into a $\mathrm{Y}$, sternum about $1 / 2$ of total length of epimerites, posterior end of sternum with transverse extensions connected to medial part of epimerites II (Fig. 1B). Coxal fields I, II without large sclerotised areas. Coxal fields I-IV closed. Rudimentary sclerites rEpIIa absent. Coxal fields IV with large sclerotised areas at bases of trochanters IV. Genital arch of moderate size, 22 (23) long, 30 (28) wide; basal sclerite of genital apparatus shaped as inverted trapezium. Aedeagus 82 (85) long, extending to midlevel of anal suckers. Genital papillae poorly distinct, situated at midlevel of genital arch. Paragenital apodemes fused to each other by their medial parts into a long median sclerite, anterior branches of these apodemes fused with inner margins of epimerites IIIa and their posterior branches fused with epimerites IV. Genital shields, epimerites IVa, posterior branches of paragenital apodemes and shield-like areas of coxal fields IV fused altogether to form almost complete sclerotised oval surrounding genital apparatus. Genital shields short and not fused to each other at 

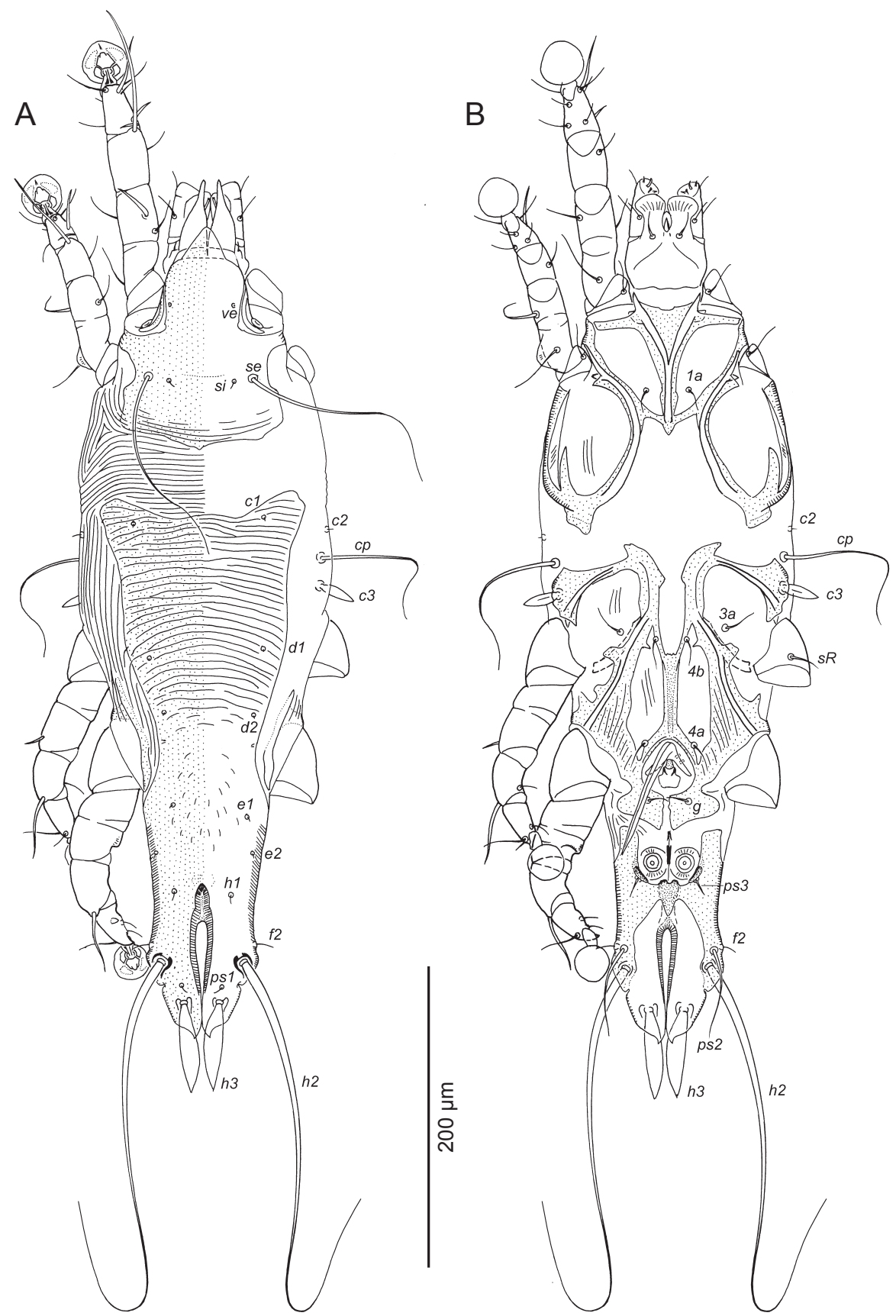

Fig. 1. Dolichodectes hispanicus sp. n., from Hippolais polyglotta (Vieillot), male. A - dorsal view; B - ventral view. Remark: setae $s R$ of trochanters III are deliberately represented as both present and absent.

midline of body. Setae $4 b$ on anterior branches of paragenital apodemes, setae $4 a$ on posterior branches of paragenital apodemes, setae $g$ on genital shields. Opisthoventral shields wide, fused together by wide transverse bridge immediately posterior to anal opening; anal field flanked posteriorly and laterally by opisthoventral shields and transverse bridge. Anal suckers 15 (13-15) in diameter, corolla without indentations. Setae $p s 3$ situated on anterior margin of transverse band connecting opisthoventral shields. Setae $4 b$ situated slightly posterior to level of setae $3 a$. Distance between ventral setae: $4 b: 4 a 70$ (68), $4 a: g 38$ (30), g:ps3 53 (52), ps3:ps 340 (42), ps3:h3 88 (86).

Legs I longer and thicker than legs II, femora II with narrow ventral crests, other segments of these legs with- out processes (Fig. 3A,B). Solenidion $\sigma 1$ of genu I 24 (22) long, situated in proximal part of segment; genual setae $c G \mathrm{I}$, II, $m G$ I, II filiform. Genu IV with narrow, heavily sclerotised ventral crest (Fig. 3D). Setae $s R$ of trochanters III absent (in holotype) or present (in paratype). Solenidion $\omega 1$ of tarsus II elongate, extending to midlevel of ambulacral disc; seta $d$ of tarsus II half as long as corresponding seta $f$. Seta $d$ of tarsus III much shorter than corresponding setae $f$. Tarsus IV 30 (31) long, with small apical claw-like process; seta $d$ hemispherical, with thick walls, situated in proximal part of this segment; seta $e$ indistinct. Solenidion $\varphi$ of tibia IV extending to midlevel of ambulacral disc. Length of solenidia: $\omega$ II 14 (13), $\omega 1$ II 23 (26), $\varphi$ I 88 (80), $\varphi$ II 53 (48), $\varphi$ III 38 (40), $\varphi$ IV 42 (37). 

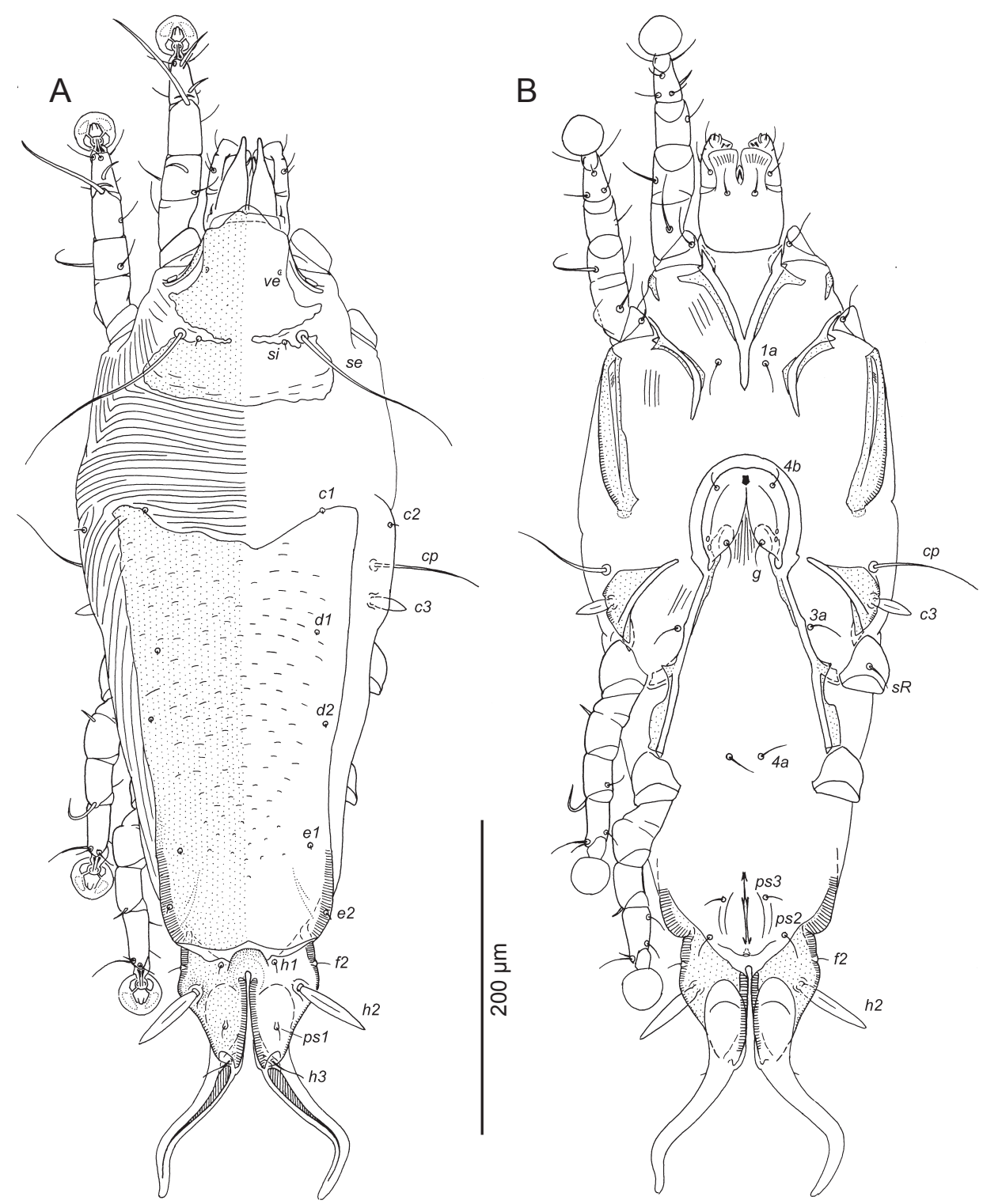

Fig. 2. Dolichodectes hispanicus sp. n., from Hippolais polyglotta (Vieillot), female. A - dorsal view; B - ventral view. Remark: setae $s R$ of trochanters III are deliberately represented as both present and absent.

Female (Figs. 2, 3E-G) (range for 4 paratypes). Length of idiosoma 520-550, width 200-210, length of hysterosoma 355-370. Prodorsal shield: anterolateral extensions narrow and free from epimerites Ia, lateral margins with deep incision at level of scapular setae, posterior margin slightly convex, length along midline $122-130$, width at posterior margin $120-125$, posterior part with transverse striae (Fig. 2A). Setae ve represented by alveoli. Bases of setae $s e$ separated by $77-80$. Humeral shields absent. Setae $c p$ and $c 2$ situated on soft tegument. Setae $c 3$ lanceolate, $22-24 \times 7-8$. Anterior and lobar parts of hysteronotal shields completely separated dorsally from each other by narrow transverse band of soft tegument, but connected ventrolaterally. Anterior hysteronotal shield noticeably enlarged in anterior part, anterior margin convex, posterior margin shaped as recurved bow, length 265-280, width at anterior margin 150-155; anterior two thirds of this shield with dash-like transverse striae. Length of lobar region $85-90$, width $90-93$, anterior margin medially convex. Ter- minal cleft narrow, with lateral margins slightly divergent, 58-62 long, about 10 wide at level of lobar apices. Supranal concavity absent. Setae $f 2$ present. Setae $h 1$ situated on anterior margin of lobar shield. Setae $h 2$ spindle-like, 52-55 long, 7-8 wide. Setae $p s 1$ approximately equidistant from inner and outer margins of opisthosomal lobes. Setae $h 3$ filiform, 12-15 long, about 1/6th length of terminal appendages. Distance between dorsal setae: $c 2: d 2125-133$, $d 2: e 2$ 115-120, e2:h2 45-50, h2:h3 43-50, d1:d2 50-57, el:e2 38-42, h1:h2 15-18, h2:ps1 20-22, h1:h1 33-35, $h 2: h 265-68$.

Epimerites I fused into a $\mathrm{Y}$, sternum about $1 / 3$ of total length of epimerites (Fig. 2B). Lateral parts of coxal fields I, II without wide sclerotised areas. Epimerites IVa absent. Translobar apodemes of opisthosomal lobes wide, not fused to each other anterior to terminal cleft. Copulatory opening situated immediately posterior to anal opening. Primary spermaduct with punctuated enlargement in most proximal part, secondary spermaducts $30-33$ long 

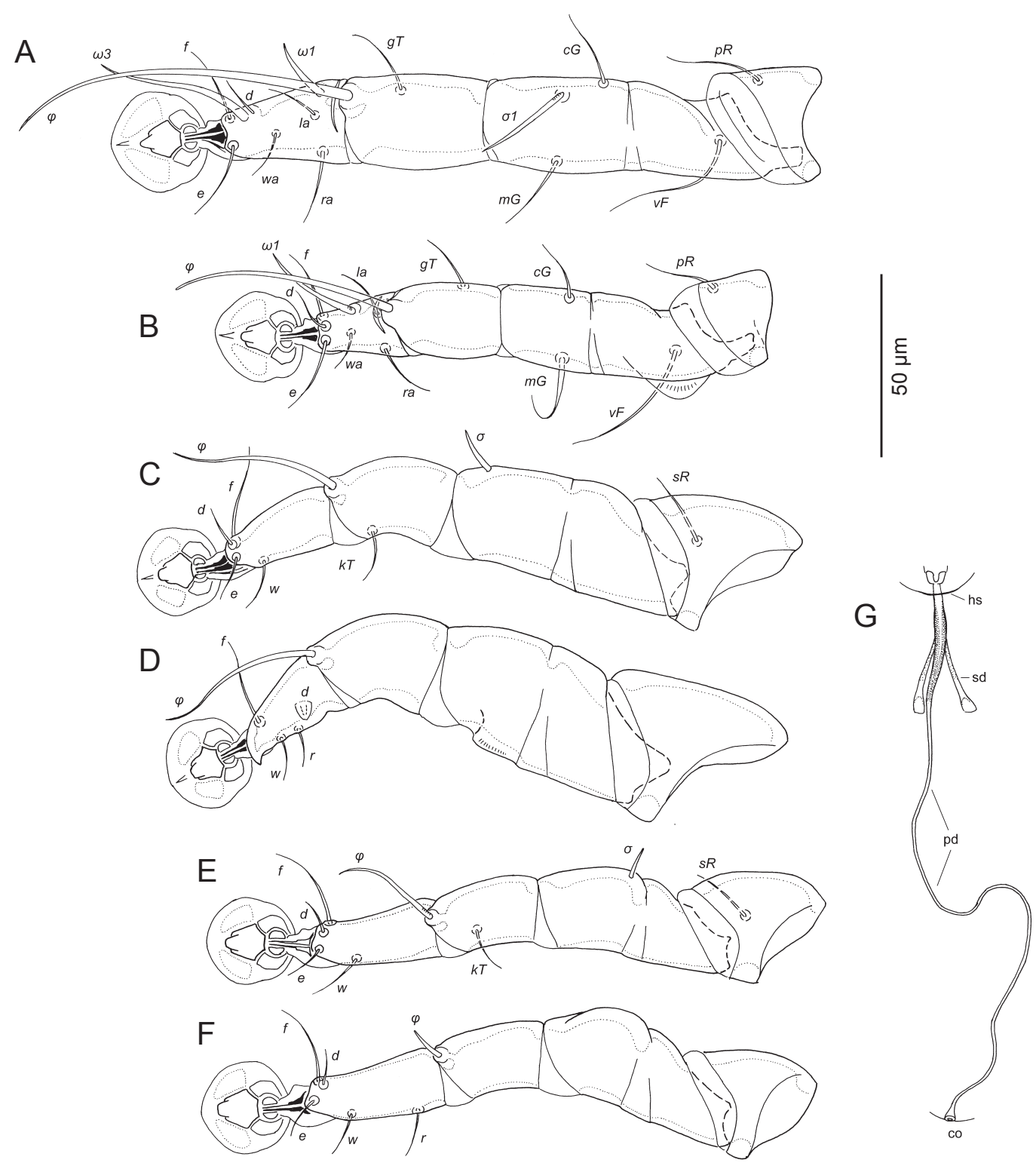

Fig. 3. Dolichodectes hispanicus sp. n., from Hippolais polyglotta (Vieillot), details. A-D - legs I-IV of male, respectively; E, F - legs III and IV of female, respectively; G - spermatheca and spermaducts. Abbreviations for Fig. 3G: co - copulatory opening, hs - head of spermatheca, pd - primary spermaduct, $\mathrm{sd}$ - secondary spermaduct.

(Fig. 3G). Distance between pseudanal setae: ps2:ps2 45-50, ps3:ps3 22-25, ps2:ps3 20-23.

Legs I, II subequal, femur II with narrow ventral crest, other segments of these legs without processes. Solenidion $\sigma 1$ of genu I 15-17 long, situated closer to anterior margin of segment. Genual setae $c G$ I, II, $m G$ I, II filiform. Genu IV with small dorsal inflation. Setae $s R$ of trochanters III absent (in 3 paratypes) or present (in 1 paratype). Setae $d$ of tarsi II-IV much shorter than corresponding setae $f$. Solenidion $\varphi \mathrm{IV}$ about $1 / 4$ of corresponding tarsus (Fig. 3F). Length of solenidia: $\omega$ II 15-16, $\omega$ III 16-18, $\varphi$ I 68-73, $\varphi$ II 52-57, $\varphi$ III 24-26, $\varphi$ IV 9-11.

Tritonymph (Fig. 4A,B,D) (range for 13 paratypes). Length of idiosoma 480-510, width 160-175, length of hysterosoma 295-310. Prodorsal shield occupying almost all prodorsum and split by T-shaped furrow into three parts, one anterior and two posterior (Fig. 4A), surface without ornamentation, total length of this shield 150-160, width at level of posterior parts 135-150. Setae ve represented by alveoli. Bases of setae se separated by $78-86$. Humeral shields absent. Setae $c p$ and $c 2$ situated on soft tegument. Setae $c 3$ lanceolate, $16-18 \times 7-8$.

Prodorsal and hysteronotal shields separated from each other by sparsely striated area of soft tegument 60-80 long. Hysteronotal shield with widely rounded anterior margin, with anterior end almost extending to level of setae $c 3$, length from anterior margin to lobar apices 245-260, width at level of setae e2 100-110, surface without ornamentation, supranal concavity present. Opisthosomal lobes long; terminal cleft between them narrow, with margins almost touching, 60-68 long. Hysteronotal setae $c 1, c 2, d 1, d 2$ situated on soft striated tegument, remaining hysteronotal setae on hysteronotal shield. Setae $d 2$ situated at level of trochanters III. Setae $h 2$ spindle-like, 30-35 × 5-6. Setae 


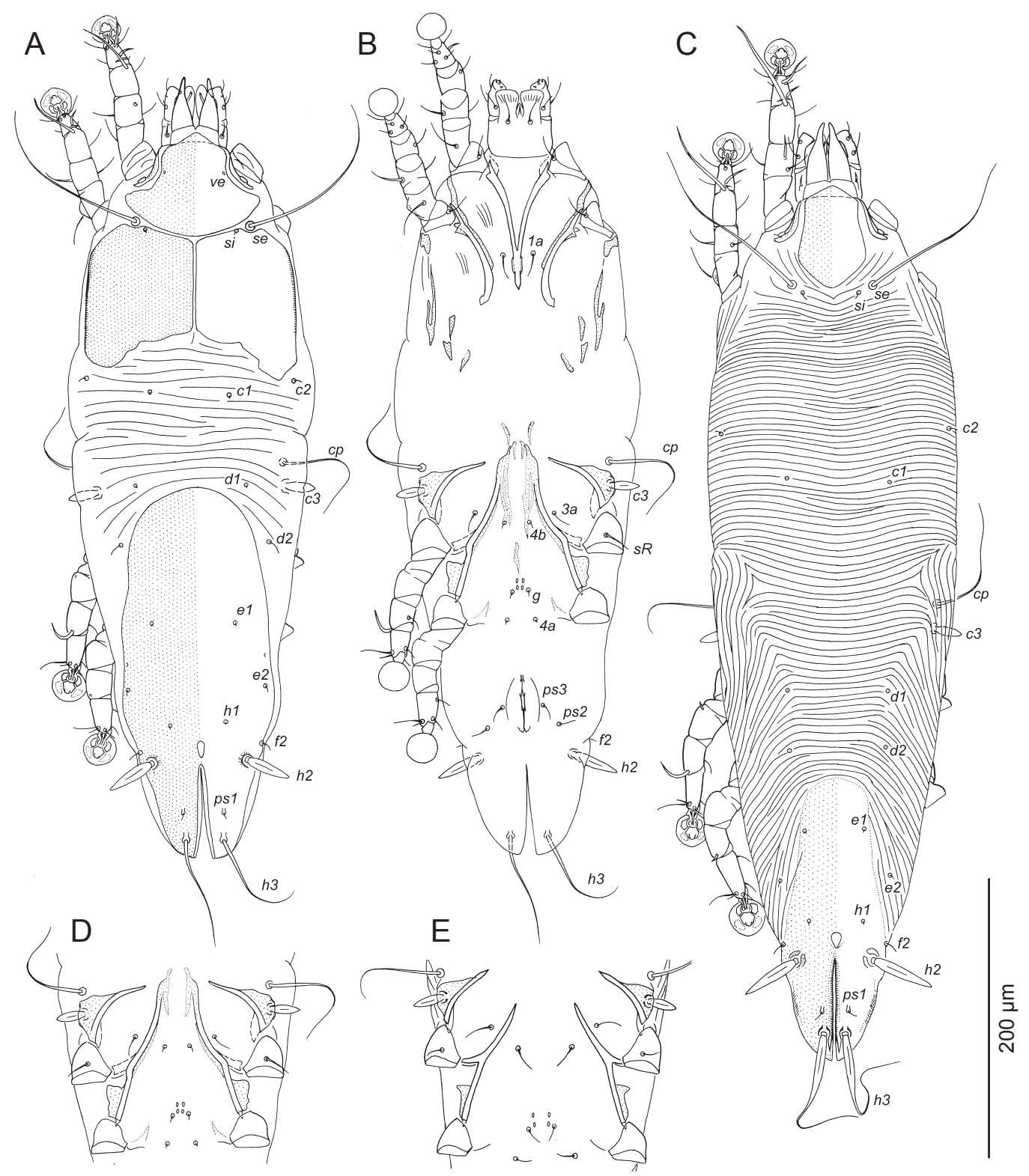

Fig. 4. Tritonymphs of Dolichodectes species. A, B, D - Dolichodectes hispanicus sp. n., from Hippolais polyglotta (Vieillot), C, $\mathbf{E}$ - Dolichodectes edwardsi (Trouessart, 1885); A, C - dorsal view; B - ventral view; D, E - coxal fields III and IV. Remark: setae $s R$ of trochanters III in D. hispanicus are deliberately represented as both present and absent.

h3 situated near lobar apices, filiform, 70-80 long. Distance between dorsal setae: $c 2: d 2$ 78-85, d2:e2 90-105, e2:h2 50-55, h2:h3 53-60, d1:d2 40-50, e1:e2 40-48, h1:h2 22-26, h2:ps1 35-40, h1:h1 38-42, h2:h2 65-73.

Epimerites I fused into a Y, sternum about $1 / 3$ of total length of epimerites (Fig. 4B). Epimerites IIa present, long, each split into 3-4 longitudinal sclerites. Inner ends of epimerites IIIa close to each other, with longitudinal sclerotised bands of irregular form; length and contour of these bands variable, sometimes but not always extending to bases of setae $4 b$ (Fig. 4B,D) . Epimerites IVa present, poorly sclerotised.

Form and setation of legs I, II as in female, except solenidion $\sigma l$ of genu I reduced to a button-like structure. Solenidion $\sigma$ of genu III absent. Setae $s R$ of trochanters III absent (in 7 paratypes) or present (in 6 paratypes). Setae $d$ of tarsi II-IV much shorter than corresponding setae $f$.
Solenidion $\varphi$ of tibia IV absent. Length of tibial solenidia: $\varphi$ I 33-36, $\varphi$ II 30-33, $\varphi$ III 11-13.

Type host: Melodious warbler Hippolais polyglotta (Vieillot) (Passeriformes: Acrocephalidae)

Type locality: Spain, Huelva, El Rocío, Doñana National Park, Manecorro, 3707'21"N; 6²9'27"W.

Date of collection: 15 October 2011, collected by R. Jovani.

Type material: Male holotype; 1 male, 4 female and 13 tritonymphal paratypes.

Deposition of type material: Male holotype (ZISP 20908), 1 male paratype (ZISP 20909), 4 female paratypes (ZISP 20904-20907), 13 tritonymphal paratypes (ZISP 20901-20903, 209010-20919).

Additional material: one tritonymph (EBD1284ART) from $H$. polyglotta, Spain, Huelva, El Rocío, Doñana National Park, Manecorro, 3707'21"N; 6²9'27"W, 5 May 2011, col- 
lected by R. Jovani; one tritonymph (EBD1286ART) from same host and location, 11 May 2011, collected by R. Jovani; one tritonymph (EBD1287ART) from same host and location, 12 May 2011, collected by R. Jovani; one tritonymph (EBD1289ART) from same host, Spain, Valencia, Tabarca, $38^{\circ} 09^{\prime} 21 " \mathrm{~N} ; 0^{\circ} 28^{\prime} 25.4^{\prime \prime} \mathrm{W}, 4$ May 2011, collected by A. Alvarez, one tritonymph (EBD1290ART), from same host and location, Spain, Valencia, Tabarca, 4 May 2011, collected by A. Alvarez.

Representative sequences: 602 bp fragment of the COI gene; GenBank accession Nos KP193461 (specimen EBD1284ART), KP193462 (EBD1286ART), KP193463 (EBD1287ART), KP193460 (EBD1289ART), KP193459 (EBD1290ART).

E t y m o log y: The specific epithet refers to the country of finding.

Differential diagnosis. The new species Dolichodectes hispanicus sp. n. is most similar to D. edwardsi described from the great reed-warbler Acrocephalus arundinaceus (Acrocephalidae) in having the following set of features (Trouessart 1885). In both sexes, the distance between the prodorsal and hysteronotal shields is relatively long, at least half as long as the length of the prodorsal shield; in males, coxal fields II are closed, opisthosomal lobes are acute apically; in females, the anterior margin of the hysteronotal shield is concave, setae $h 3$ are short and do not exceed $1 / 4$ the length of the terminal appendages.

Dolichodectes hispanicus differs from $D$. edwardsi by the following features: in males, the aedeagus is $78-84 \mu \mathrm{m}$ long and extends to the midlevel of anal suckers (Fig. 1B), length of the terminal cleft is $82-85 \mu \mathrm{m}$. In females, the anterior hysteronotal shield is shorter and relatively wider (the greatest length $265-280 \mu \mathrm{m}$, ratio of the length to greatest width 1.7-1.8), length of idiosoma is $520-550 \mu \mathrm{m}$.

In males of $D$. edwardsi $(\mathrm{n}=10)$, the aedeagus is 95-100 $\mu \mathrm{m}$ long and slightly extends beyond the posterior margin of anal suckers, the terminal cleft is $100-110 \mu \mathrm{m}$ long. In females $(n=10)$, the anterior hysteronotal shield is longer and narrower (the greatest length $285-315 \mu \mathrm{m}$, ratio of length to greatest width is 2.0-2.2), length of idiosoma is $560-610 \mu \mathrm{m}$.

Whilst adults of $D$. hispanicus and D. edwardsi are very similar in their general appearance and differ from each other by mensurative characters, the morphological difference between tritonymphs of these species is much more conspicuous. In tritonymphs of $D$. hispanicus, the prodor- sal shield covers almost the entire prodorsum and is split by T-shaped furrow into 3 pieces (one anterior and a pair of posterior plates), the hysteronotal shield extends to the level of subhumeral setae $c 3$, transverse striae on the area between the prodorsal and hysteronotal shields are sparse, setae $h 3$ are filiform, solenidion $\sigma l$ of genu I is reduced to a small button, epimerites IIIa extend to the level of tips of epimerites III and bear longitudinal sclerotised bands, and epimerites IIa are present and split into several longitudinal sclerites (Fig. 4A,B,D).

In tritonymphs of $D$. edwardsi, the prodorsal shield is represented by an entire plate covering only the median part of the prodorsum anterior to scapular setae, the hysteronotal shield extends to the level of trochanters IV, striation between dorsal shields is as dense as in adults, setae $h 3$ are spindle-shaped basally, solenidion $\sigma l$ of genu I is normal setiform, the tips of epimerites IIIa are simple and do not extend to the level of epimerites III, and epimerites IIa are strongly reduced (Fig. 4C,E).

References DNA sequences. The average genetic distance among all specimens, in which sequences were examined, was $0.6 \%$ (SE 0.2). All nucleotide substitutions were synonymous. All sequences were identified as belonging to the same Barcode Index Number (BIN; ACR0931).

Remark. It is interesting to note an unstable state of the trochanteral seta $s R I I I$ in Dolichodectes hispanicus of adults and in tritonymph. In pterodectines of the Pterodectes generic group, the presence or absence of this seta is stable in species, and a state of this character is usually a good diagnostic feature for a genus. This character varies among species only in the genus Montesauria Oudemans, 1905 (Mironov et al. 2008, 2012, Mironov and Tolstenkov 2013).

Acknowledgements. Funding for the field and laboratory work was provided by the Spanish Ministry of Economy and Competitiveness (Ramón y Cajal research contract RYC-2009-03967 to RJ, and research project CGL2011-24466 to RJ; SVP-2013067939 from the Severo Ochoa Program SEV-2012-0262 to JD); SM was supported for this study by the Russian Foundation for Basic Research (Grant No 13-04-00608a). Special thanks to Alberto Álvarez (Estación Ornitológica Anastasio Senra bird ringing group, Aroche, Spain) for the samples provided, to José Luis Arroyo and his team for their support in the Manecorro bird ringing station, to Javier Díaz-Real (Universidade de Vigo, Vigo, Spain) for the laboratory work, and Miroslawa Dabert (A. Mickiewicz University, Poznań, Poland) for her advice on lab protocols.

\section{REFERENCES}

Atyeo W.T. 1973: Feather mites. In: H.E. McClure and N. Ratanaworabhan (Eds.), Some Ectoparasites of the Birds of Asia. Jintana Printing Ldt., Bangkok, pp. 54-78.

Clements J.F., Schulenberg T.S., Iliff M.J., Sullivan B.L., Wood C.L., Roberson D. 2014: The eBird/Clements checklist of birds of the world: Version 6.9, http://www.birds.cornell.edu/ clementschecklist/download/, 11/2014.

Doña J., Diaz-Real J., Mironov S., Bazaga P., Serrano D., JovANi R. 2015: DNA barcoding and mini-barcoding as a powerful tool for feather mite studies. Mol. Ecol. Res.: (in press).
Gaud J., Atyeo W.T. 1996: Feather mites of the world (Acarina, Astigmata): the supraspecific taxa. Ann. Mus. R. Afr. Centr., Sci. Zool. 277: 1-193 (Part 1, text), 1-436 (Part 2, illustrations).

Gaud J., Mouchet J. 1957: Acariens plumicoles (Analgesoidea) des oiseaux du Cameroun. I. Proctophyllodidae. Ann. Parasitol. Hum. Comp. 32: 491-546.

Gaud J., Till W.M. 1961: Suborder Sarcoptiformes. In: F. Zumpt (Ed.), The Arthropod Parasites of Vertebrates in Africa South of the Sahara (Ethiopian Region), Volume 1 (Chelicerata). Publ. South Afr. Inst. Med. Res., I (IX), Johannesburg, pp. 180-352. 
Hernandes F.A., VAlim M.P. 2006: Two new species of the feather mite subfamily Pterodectinae (Acari: Astigmata: Proctophyllodidae) from Brazil. Zootaxa 1235: 49-61.

Kimura M. 1980: A simple method for estimating evolutionary rate of base substitutions through comparative studies of nucleotide sequences. J. Mol. Evol. 16: 111-120.

Krantz G., Walter D. (Eds.). 2009: A Manual of Acarology, Third Edition. Texas Technical University Press, Lubbock, 807 pp.

Mironov S.V. 1996: [Feather mites of the passerines in the NorthWest of Russia.] Parazitologiya 30: 521-539. (In Russian.)

Mironov S.V. 2009: Phylogeny of feather mites of the subfamily Pterodectinae (Astigmata: Proctophyllodidae) and their host associations with passerines (Aves: Passeriformes). Proc. Zool. Inst. RAS 313: 97-118.

Mironov S.V., FAin A. 2003: New species of the feather mite subfamily Pterodectinae (Astigmata: Proctophyllodidae) from African passerines (Aves: Passeriformes). Bull. Soc. R. Belg. Entomol. 139: 75-91.

Mironov S.V., González-Acuña D. 2011: New feather mites of the subfamily Pterodectinae (Astigmata: Proctophyllodidae) from passerines (Aves: Passeriformes) from Chile and Cuba. Zootaxa 2037: 1-48.

Mironov S.V., LiteráK I., ČAPEK M. 2008: New feather mites of the subfamily Pterodectinae (Acari: Astigmata: Proctophyllodidae) from passerines (Aves: Passeriformes) in Mato Grosso do Sul, Brazil. Zootaxa 1947: 1-38.

Mironov S.V., LiteráK I., ČAPeK M, KoubeK P. 2010: New species of the feather mite subfamily Pterodectinae (Astigmata: Proctophyllodidae) from passerines in Senegal. Acta Parasitol. 55: 399-413.
Mironov S.V., Literák I., NGuen M.H., ČAPeK M. 2012: New feather mites of the subfamily Pterodectinae (Acari: Proctophyllodidae) from passerines and woodpeckers (Aves: Passeriformes, Piciformes) from Vietnam. Zootaxa 3440: 1-49.

Mironov S.V., Tolstenkov O.O. 2013: Three new feather mites of the subfamily Pterodectinae (Acari: Proctophyllodidae) from passerines (Aves: Passeriformes) in Vietnam. Proc. Zool. Inst. RAS 317: 11-29.

NORTON R. 1998: Morphological evidence for the evolutionary origin of Astigmata (Acari: Acariformes). Exp. Appl. Acarology 22: 559-594.

Park C.K., Atyeo W.T. 1971: A generic revision of the Pterodectinae, a new subfamily of feather mites (Sarcoptiformes: Analgoidea). Bull. Univ. Nebraska State Mus. 9: 39-88.

Ratnasingham S., Hebert P.D. 2013: A DNA-based registry for all animal species: the Barcode Index Number (BIN) system. PloS ONE 8: e66213.

Tamura K., Stecher G., Peterson D., Filipski A., Kumar S. 2013: MEGA6: Molecular Evolutionary Genetics Analysis Version 6.0. Mol. Biol. Evol. 30: 2725-2729.

Trouessart E.L. 1885: Note sur le classification des Analgésiens et diagnoses d'espèces et de genres nouveaux. Bull. Soc. Etud. Sci. Angers 14: 46-89.

VAlim M.P., Hernandes F.A. 2009: A new species of the feather mite genus Cotingodectes and a new genus of Pterodectinae (Astigmata: Proctophyllodidae). Int. J. Acaro. 35: 265-272.

Valim M.P., Hernandes F.A. 2010: A systematic review of feather mites of the Pterodectes generic complex (Acari: Proctophyllodidae) with redescriptions of species described by Vladimír Černý. Acarina 18: 3-35.

Cite this article as: Mironov S.V., Doña J., Jovani R. 2015: A new feather mite of the genus Dolichodectes (Astigmata: Proctophyllodidae) from Hippolais polyglotta (Passeriformes: Acrocephalidae) in Spain. Folia Parasitol. 62: 032. 